\title{
Using wireless and mobile technologies to enhance teaching and learning strategies
}

\author{
Kahkashan Tabassum \\ Deapartment of Computer Science (CCIS), Princess NourahBint Abdulrahman University, Saudi Arabia
}

\begin{abstract}
Article Info
Article history:

Received Jul 10, 2019

Revised Sep 12, 2019

Accepted Sep 26, 2019

\section{Keywords:}

Artificial intelligence

Autism

Children literature

Communication skills

Intelligent application

Learning skills

Reading skills

ABSTRACT

The tremendous development and sensational popularity of smart mobile devices that offer uninterrupted communication services could be utilized for inculcating creative skills in young children. Many tools and applications that target children education and entertainment are easily available these days. Both parents and educators find a huge responsibility in evaluating and selecting such devices and decide which of these offer potential educational benefits for their children, decision seems critical for them since they use restricted tools to evaluate the applications available in the market. Hence the development of an interactive and multisensory component based mobile application environment with integrated physical and virtual reality scenario could solve the issue related to the children education and entertainment. This is not just limited to education and the entertainment domain but will explore essential features of virtual reality environment and interactivity. Children with special education needs face difficulties in understanding new information and concept but by the use of virtual reality worlds, their level of understanding could be improved. This paper discusses the development of adaptable, customizable and virtual reality based compliant applications for children. These applications may be useful to enhance learning essentials and improve diverse sensory and cognitive impairments in children with special needs. This paper discusses development of application that could be made available on i-pads, tablets, etc and will be intelligent to perform switch between the different intellectual ranges of children accessing it. In other words it will present self-adaptability feature. This research study also focuses on the activities that are suitable for learning purposes with students with impairments.
\end{abstract}

Copyright () 2020 Institute of Advanced Engineering and Science. All rights reserved.

\section{Corresponding Author:}

Kahkashan Tabassum,

Department of Computer Science (CCIS),

Princess Nourah Bint Abdulrahman University,

Riyadh, Saudi Arabia.

Email: ktosman@pnu.edu.sa

\section{INTRODUCTION}

The huge progress in technology and applications in Artificial Intelligence, the ease of availability of mobile devices and hypermedia awareness among the young children are is creating a lot of attraction towards accessing computer resources. The consequences of negative impact as most people believe are that the use of technology in the form of i-pads or laptops enabled with internet connectivity with multimedia entertainment, online games or activities, social interaction may lower the opportunities for physical development and team attitude among children. But on the other hand the technological advances have created a hybrid of interactive educational applications into the homes of children -such a revolutionary achievement. The digital world can provide a variety of phonological awareness activities and can assist to deliver feedback to students and present reports to teachers about progress of their students [1]. 
The proliferation of interaction devices based on Multimedia resources have given rise to a wide range of learning strategies based on platforms integrated with sound, text, animated images, video media. These platforms [2, 3] use different modes of input such as typing, speaking, pointing devices. These platforms could be used to create various interactive applications for children involving activities such as matching images based on sound or even guess the beginning alphabet, identify a sequence of sounds based when the words merged together, rhyming words, etc. These activities supported by the computer interaction could be extended to create advance activities that will enable the children to participate to contribute their literature and ideas for literary purpose. Not only this the young minds can generate their views on the teaching [4] learning processes from the children's' perspective to make the process more effective. The students could make contributions towards the literature corresponding to their capabilities either by writing stories, poems, posters, share their views on a topic with other students, participate in competitions involving literature and improve further by continuous development in this area. This research strived to provide a multipurpose interactive learning environment to normal as well as impaired children, study the problems and difficulties faced by the children to read and learn, analyzes their interests in different educational activities and guide them with the appropriate levels and environments of learning, creation of integrated environment capable of following actions, provide a secure platform since the digital technology is so ubiquitous that it needs protection and benchmark results of comparison during their academic progress to determine the change of behavior among children.

\section{LITERATURE SURVEY}

This generation is the age of technology, where the world has become dependent on electronic devices not only in calls and but in professional using. Even the children have a share of this, there are those physical tools such as games and puzzles and educational applications that fit their age and develop their intellectual and interactive skills. However, do not forget to mention the applications of stories for children, stories because of the guidance of the child and gain lesson and good morals. However, most applications are not effective for several reason such as Lack of interaction between them and the child, while most applications, show the story only without anything that may attract children such as games, or competitions and coloring. Some applications have interfaces that do not attract the children and they may feel bored. No application containing multiple languages, most applications are from unknown religious sources or unknown authors. During the years of children, aged 4-10 [1,5] they learn to take the initiative in socially acceptable ways and they are keen to have an experience in what is happening in their surroundings. Therefore, the child starts using the iPad and mobile devices and learns about the applications so, this age group who are the beneficiaries of applying the stories, science and mathematics subjects [6].The colors were chosen in the application according to what attracts the children. The nature of the child tends to bright colors such as yellow, red, blue, green and always has a wide imagination so; our application contains a voice, which works at the same time with the pictures to attract the attention of the child. The coordination and the integration of colors will be decided in the application according to the child's personality, imagination and mind as was used in [7,8]. As multi touch technologies and other emerging user interface possibilities are more affordable and available, new research is needed on what young children are able to do and how these tools and media can be integrated. Research-based evidence about what constitutes quality technology and interactive media for young children is needed to guide policy and inform practice and to ensure that technology and media tools are used in effective, engaging, and appropriate ways in early childhood programs. The research targets the creation of mobile application and supporting for improvement and enhancement of children education and entertainment.

Mobile applications [9, 10] have made the handheld devices a crucial part of daily life and provide communication and entertainment. Therefore the educators attempt to enable learning [11] by the application of recent mobile technologies and devices such as smart phones, i-pads etc. for providing appropriate learning strategies to support children. Smart phones are based on functionalities such as location tracker, high resolution camera, internet connectivity, downloadable application of various types, embedded context aware sensors and other advance mobile technology $[10,12,13]$ that provide interactive multimedia learning content for instructional and entertainment purposes.

With wireless mobility children(students) can obtain participation in learning activities and can connect to their peers around the world. Mobile devices or smart phones are handheld easy-to-use devices are deployed as learning tools in both learning contexts [14]that can deliver information effectively, in any situation staying away from the place the students can access this information and thus the mobile learning can assist the children in learning and education $[15,16]$. It is therefore evident from many research results that the handheld smart phones are used widely in learning and collaborative context by students as mobile learners [14]. 
The technology nowadays can be used as an assessment tool to measure the educational potential of children of different age groups [17]. The current knowledge about children's cognitive and social abilities can be useful for the development of computer based applications. The following section provides the insight of the target tasks for children software development and accomplishment details. There are THREE phases [18] of the software platform/tool (Figure 1) for enhancing education skills in children.

\section{RESEARCH METHOD}

In this section we discuss as to how we can achieve the first objective of the research which was described in [18]. Some children are weak at grasping a particular concept and hinders good learning capabilities.

\subsection{Multipurpose Interactive Mobile Learning Environment}

The following section explains the strategy of providing interactive learning environment to normal as well as impaired children. Few children suffer with disorders that can be categorized as lacking effective learning skills are considered to be different from normal children. They suffer with a learning disability issue which is considered as growing disorder among children that effects the learning capabilities of children in a specific domain such as reading (writing or solving arithmetic problems). Medically some children are not very sound in their learning and cognitive skills and are considered to possess learning disabilities or disorders of type dyslexia, dyscalculia, dysgraphia or deficit disorder of concentration useful to learning). Other types of disorders include genetic disabilities classified to be autism, down syndrome and congenital birth defects that of partially affect the cognition in children. These children may suffer from the difficulty when showing their reading and writing skills. They are different than their peers in terms of reasoning and cognitive skills, they may find difficulty in quick organization of information since their spelling, recalling and recognition skills are less in comparison to their peers. This requires that the conventional strategies can be enhanced and with the parental support these children would be able to improve their learning skills and succeed in their future careers. These disorders are classified as autism and are related to autism spectrum disorders for inculcating growth disabilities among children. The effect of autism is seen as significant impairments in the activities of children, in their communication, emotional and social interactivity since they weird attitude and interests. The autistic children may have their own methods of learning, concentrating and reaction to a situation different from normal children [5].

In this paper, we will discuss the development of integrated and intelligent mobile (android) application for autistic's learning. Mobile application development technology is being used in almost every aspect of human life [19] to facilitate the development of evolving, intelligent, smart and IoT (Internet of Things) as a solution to the wide range of problems found in any field. Now a days mobile applications are aimed at the production of high-quality applications with more cost-effective and short life cycles and could be used and modified as per requirement in short time [20]. By understanding the requirements from the endusers' perspective such as parents, teachers, managers administrators responsible for understanding needs of such children the mobile application could be a smart solution.

Also it factual that every child is attached to his/her mother and therefore the effect of any suggestion to the child is more effective if it is from mother. Also in some cases the teacher also is found very close to the teacher. The interface would be supported by a voice application which can be tuned in the voice of mother or of their favorite teacher. The application is adaptable and intelligent to predict the choices of the child and apply those options to motivate the child to use the interface. We apply the methods given in [5] for teaching young autistic children aged between 0 to 6 years as summarized below.

\subsubsection{Gross Motor Skills (GMS)}

The first level interface of application will develop support for GMS. These Skills refer to the activities related to movement and mobility like controlling self- body and head, learning to sit, kick, jump, roll, crawl, stand, walk up or down staircase, playing skills catch, throw, hit a ball, cycle riding. Level I interface for supporting GMS as shown in Figure 1. 


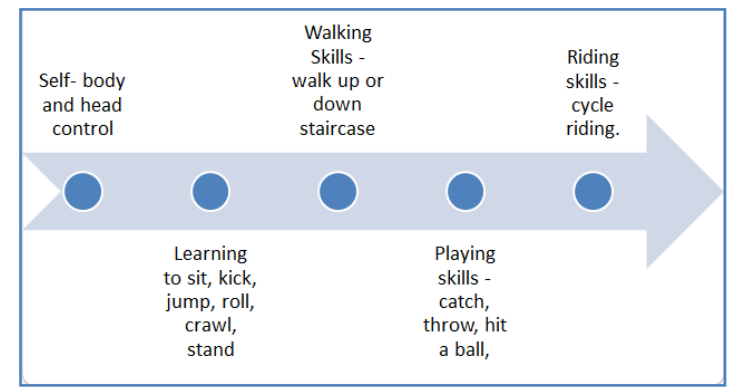

Figure 1. Level I interface for supporting GMS

\subsubsection{Fine Motor Skills}

These Skills are based on effective hand using ability of children involving eye to hand coordination including skills like vision, explore and manipulate objects, completing shape, puzzles and words. Some example arts are defined below learning pre-drawing, drawing and coloring skills. Level II interface for supporting FMS as shown in Figure 2.

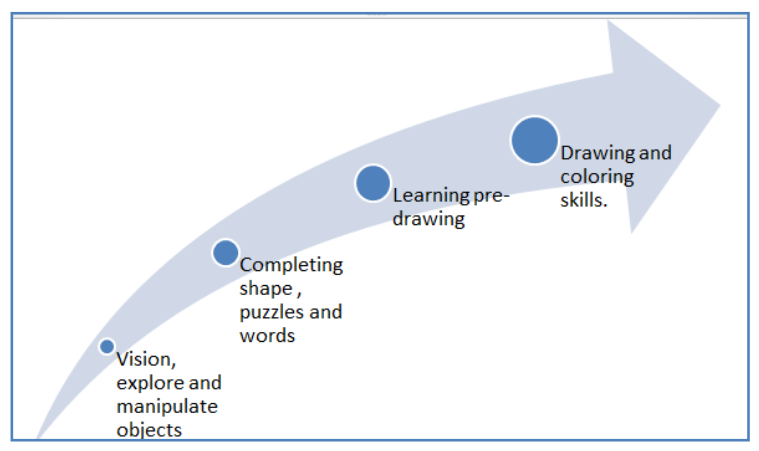

Figure 2. Level II interface for supporting FMS

\subsubsection{Self Help Skills (SHS)}

These set of skills are grouped into level III organization of the interface. These skills include everyday life activities as feeding, drinking, washing and brushing Hair. Level III interface supporting SHS as shown in Figure 3.

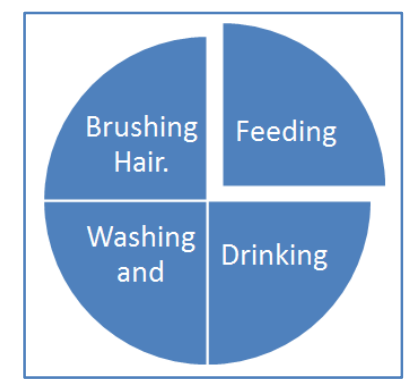

Figure 3. Level III interface supporting SHS

\subsubsection{Language Development}

This is developed as level IV support for mobile application development interface. The child's ability to speak different words and make sentences, understand the context of speech of people around including their hearing, receptive, expressive, reading and writing skills. 
The application will provide support to train the children in development of the various learning skills aspects. The most important skills that support a child to stand in the world today shouldering many others are reading, writing and communication skills. Level IV interface - language development as shown in Figure 4.

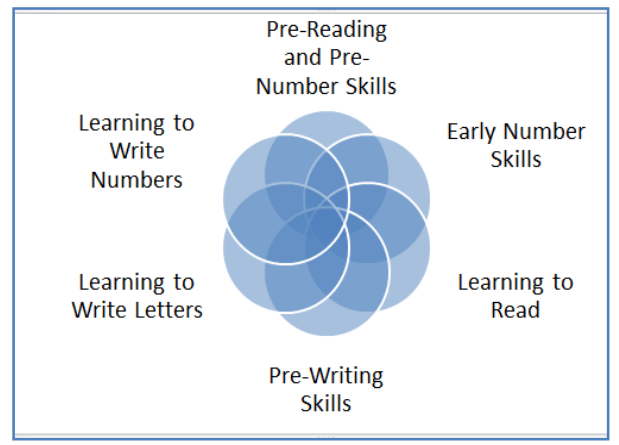

Figure 4. Level IV interface - language development

\subsubsection{Social Development (Level V-interface support of application development)}

Children should be able to maintain social communication and interaction skills for their social development and movement in society. Use of social networking websites and applications such as facebook, twitter, instagram, whatsapp, etc could help the children to collaborate with their fellow children to participate as well as learn the social movement and behavior.

\subsubsection{Miscellaneous (Level VI)}

The final level of supporting interface for autistic children contains following options:

a) Children Profile menu option that consists of name, identifier of the child group based on their choices and feeling.

b) History and Evaluation menu option to maintain of forgotten activities by the child.

c) Other Activities (for Future use)

d) Gaming

\section{RESULTS AND DISCUSSION}

This following section illustrates the intended results of the proposed application with respect to the six(6) steps as explained in the previous section to develop six levels of integrated interface that has IoT support to train children in an effective manner. IoT is an upcoming digital transformation technology that is used to interconnect virtual environment with the physical (real ) environment. Figure 5 shows a screen shot for Level III - development of mathematical skills support for impaired children aged between 6-7 years.

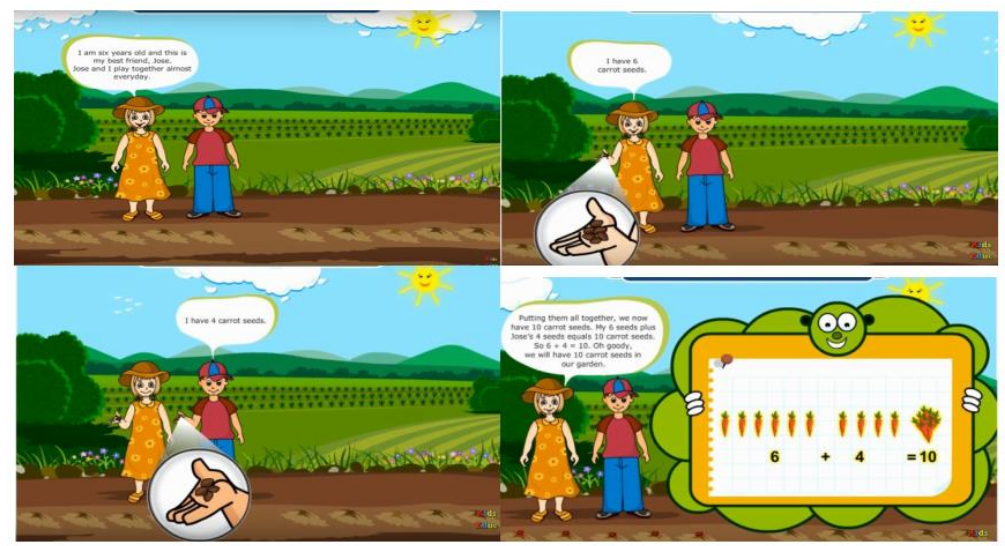

Figure 5. Level III - Development of mathematical skills support for impaired children 
Some of the research studies conducted in this area examined children's learning performance and efficiency by making every child interact with a range of Mobile iPad applications and the test for mathematics learning on these touch screens show that the performance using iPad applications on touch screens for children was better [21-23] when compared to other traditional methods while some researches $[24,25]$ showed no noteworthy differences on use of touch-screen gadgets for mathematics learning. Therefore we proposed a new method that uses latest technology of IoT for improving the results further. The proposed method is expected to reflect more trends in the research based on children of different age groups responding in a different manner.

\section{CONCLUSION}

Computer resources such as audio and video, text and images, spoken words and illustrations, graphics design, illustrations and annotations, scenarios, interactive storyboards, hyperlinks and socially active networks are useful to produce layered or hierarchical understanding among children. It is obligatory on a teacher to be abridged with the fast growing collections and applications related to digital children's literature. Although Nonetheless the educators were interested in using technology for providing assistance to readers but it had less focus on its usage, however it is possible to allow children to use digital children's literature. As of today e-learning has become common and hence literacy instruction sing technology for increasing reading performance widely accepted for developing reading skills among children that involve appropriate reading activities. The learning skills can enhance the overall development of fluency, writing and comprehension skills.

\section{ACKNOWLEDGEMENTS}

This research is funded by Princess Nourah Bint Abdulrahman University (PNU), Children's Literature Research Centre (CLRC) and Saudi British Centre (SBC) under the Grant No. CLS2018-08. I am thankful to the Research Unit for their constant support and encouragement to improve the research skills of the researchers at Princess Nourah University.

\section{REFERENCES}

[1] Chaudron S., "Young Children (0-8) and digital technology", Luxembourg: Publications Office, 2015.

[2] Mohd A. Zin. "Block-Based Software development", Programming and Software Technology Research Group Technical Report, Universiti Kebangsaan Malaysia, January2008.

[3] Nierstras O. and L. Dami, "Component-Oriented Software Technology", In Oscar Nierstrasz and Dennis Tsichritzis", editors, Object-Oriented Software Composition, pages 3-28. Prentice Hall, 1995.

[4] Koehler M. J. and Mishra P., "What is technological pedagogical content knowledge?", Contemporary Issues in Technology and Teacher Education (CITE Journal), vol. 9(1), pp. 60-70, 2009

[5] Della R., "A Curriculum Guide for Teaching Young Mentally Handicapped Children”, Malaysian CARE, 1996.

[6] Hannafin, M.J.,"Emerging technologies, ISD, and learning environments: Critical perspectives", Educational Technology Research and Development, Vol. 40(1): pp. 49-63, 1992.

[7] Costabile M. F et al., "Software Environments for End-User Development and Tailoring", Psychology Journal, Volume 2, No. 1, pp. 99-122, 2004.

[8] Hooper, S. and Hannafin, M.J., "Psychological perspectives on emerging instructional technologies: A critical analysis", Educational Psychologist, Vol. 26, pp. 69-95, 1999.

[9] Mandryk, R. L. et al., " Supporting children's collaboration across handheld computers", Proceedings of Conference on Human Factors in Computing Systems, Seattle, USA, 2001.

[10] Sakamura, K. and Koshizuka, N., "Ubiquitous computing technologies for ubiquitous learning", Proceeding of the International Workshop on Wireless and Mobile Technologies in Education, Los Alamitos: IEEE Computer Society, pp.11-18, 2005.

[11] Chen, Y. S. et al., "Realizing outdoor independent learning with a butterfly-watching mobile learning system", Journal of Educational Computing Research, Vol. 33(4), pp. 395-417, 2005

[12] El-Bishouty et al., "PERKAM: personalized knowledge awareness map for computer supported ubiquitous learning", Educational Technology \& Society, Vol. 10(3), pp. 122-134, 2007.

[13] Lundin, J., and Magnusson, M., "Collaborative learning in mobile work", Journal of Computer Assisted Learning, vol. 19, pp 273-283, 2001.

[14] Zurita, G. and Nussbaum, M., "A Constructive Mobile Learning Environment supported by a Wireless Handheld Network”, Journal of Computer Assisted Learning, vol. 20, pp. 235-243, 2004.

[15] Ghiani, G., et al., "UbiCicero: a location-aware, multi-device museum guide", Interacting with Computers, doi:10.1016/j.intcom.2009.06.001, 2009.

[16] Hwang, G. J. et al., "A context-aware ubiquitous learning environment for conducting complex science experiments", Computers \& Education, Vol. 53, pp. 402-413, 2009. 
[17] Selwyn, N., "Sharpening the "ed-tech imagination:Improving Academic Research in Education and Technology". Keynote presentation to the Critical Perspectives on Learning with New Media Conference, Monash University, Australia, pp. 6-16, 2012

[18] Kahkashan Tabassum, “An Intelligent Self-Adaptable Application to support children Education and Learning”, International Journal of Computer Science Information Technology (IJCSIT), Vol. 10 No. 6, pp. 24-30, December 2018.

[19] Charlton J. and I. Danforth, "Distinguishing addiction and high engagement in the context of online game playing", Computers in Human Behavior, Vol. 23, no. 3, pp. 1531-1548, 2007.

[20] Selwyn, N, "Looking beyond learning: Notes towards the critical study of educational technology", Journal of Computer Assisted Learning, 26(1), 65-73. doi: 10.1111/j.1365-2729.2009.00338.x, 2010.

[21] Liu, N. S, “ iPad infuse creativity in solid geometry teaching”, Turkish Online Journal of Education Technology, Vol. 12(2), pp. 177-192, 2013.

[22] Riconscente, M. (2012). Mobile learning game improves 5th graders' fractions knowledge and attitudes (p. 46). Los Angeles, California: GameDesk Institute.

[23] [24] Spencer, P., "iPads: Improving numeracy learning in the early years", V. Steinle, L. Ball, \& C. Bardini (Eds.), Mathematics education: Yesterday, today, and tomorrow, pp. 610-617. Melbourne, Australia, 2013.

[24] Zimmerman, S. and Howard, B., "Implementing ipads into K-12 classrooms: A case study", Society for Information Technology \& Teacher Education International Conference, Vol. (1), pp. 2512-2516, 2013.

[25] Carr, J. M., "Does math achievement h'app'en when iPads and gamebased learning are incorporated into fifthgrade mathematics instruction?", Journal of Information Technology Education: Research, Vol. 11, pp. 269-286, 2012.

\section{BIOGRAPHIES OF AUTHORS}

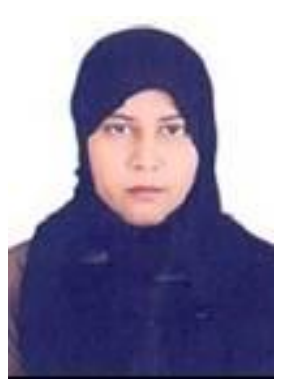

Dr. Kahkashan Tabassum Department of Computer Sciences, College of Computer and Information Sciences, Princess Nourah bint Abdulrahman University, Kingdom of Saudi Arabia. She is currently working as a computer sciences faculty in college of Computer and Information Sciences in PNU. She received her Ph.D. (Computer Science Engineering) and her M. Tech (Computer Science and Engineering) from Jawaharlal Nehru Technological University, Hyderabad, India. Her area of interests are Database Management Systems, Mobile Computing, Cloud Computing, Network Security and Data Mining. She has published more than 50 technical papers in National, International conferences and journals. She is an active researcher and her current research projects are based on the areas, Internet of Things and Health Informatics, Cyber Security, Human Computer Interaction. 